\title{
Implementation Through Innovation: A Literature-Based Analysis of the Tuning Project
}

Krisztián Pálvölgyi*,a, b

${ }^{a}$ Corvinus University of Budapest, Hungary

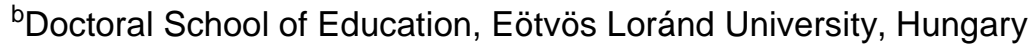

Submitted: July 10, 2017 | Peer reviewed: August 19, 2017 | Accepted: September 7, 2017 |

Published: October 26, 2017

\begin{abstract}
Tuning Educational Structures in Europe is perhaps the most important higher education innovation platform nowadays. The main objective of the Tuning Project is to develop a tangible approach to implement the action lines of the Bologna Process; thus, implementation and innovation are closely linked in Tuning. However, during its development, Tuning has evolved into a complex, multilevel policy implementation toolset with a worldwide significance. The purpose of this article is to present the complex nature of the Tuning Project, the environment and dynamics of its development, and the mechanisms of its operation from a multilevel implementation perspective, through a literature-review-based analysis.
\end{abstract}

Keywords: Tuning Project, Bologna Process, implementation, innovation, learning outcomes

\section{Introduction}

During the last 18 years, the Bologna Process was the driving force behind European higher education reforms. Its main goal was to create the European Higher Education Area (EHEA), where higher educational institutions work with common approaches and use common tools. The aims and developments of the Bologna Process fundamentally affect the operation of higher education institutions in Europe, especially their learning and teaching practices. The Tuning Educational Structures in Europe project is a main implementation tool of the Bologna Process, but its impact exceeds the borders of the EHEA. Due to its scale, worldwide significance, and complexity, Tuning is perhaps the most important higher education innovation platform and implementation environment nowadays.

The current study aims to interpret the complex nature of the Tuning Project through literature-based analysis. Through the overview and interpretation of experiences expressed in Tuning-related literature, the study analyzes how Tuning works. The main focus is on the environment and dynamics of Tuning's development and the mechanisms of its operation. To ensure the deeper understanding of such a complex higher education project, the current analysis builds upon literature on implementation theory, organizational change in higher education, and higher education policies in addition to Tuning-specific sources. These perspectives make it possible to comprehend tuning-specific experiences better and, through that, to better understand the nature of large-scale higher education reforms.

\section{The Bologna Process: Context of the European Higher Education Reform}

The Bologna Process was brought to life in 1999 with the intention of creating the EHEA within a decade. To achieve this goal, 10 action lines have been formulated (Luzzatto, 2011;

\footnotetext{
*Author correspondence: krisztian.palvolgyi@uni-corvinus.hu

Suggested Citation: Pálvölgyi, K. (2017). Implementation through innovation: A literature-based analysis of the Tuning Project. Higher Learning Research Communications, 7(2). http://dx.doi.org/10.18870/hlrc.v7i2.380
} 
Witte, 2006): (a) adoption of a system of easily readable and comparable degrees, (b) adoption of a system essentially based on two cycles, (c) establishment of a system of credits, (d) promotion of mobility, (e) promotion of European co-operation in quality assurance, (f) promotion of the European dimension in higher education, (g) focus on lifelong learning, (h) greater inclusion of higher education institutions and students in the Bologna Process, (i) promotion of the attractiveness of the EHEA, and (j) doctoral studies and the synergy between the EHEA and the European Research Area.

European higher education-for which the above-listed objectives have been formulated-is a rich world of institutions with different traditions and with a conventionally high degree of autonomy. From this point of view, it is an important historical detail that the Bologna Process was initiated not at the supranational but at the national level. The education ministers of France, Germany, Italy, and the United Kingdom signed the Sorbonne Declaration in 1998 to foster the harmonisation of their higher education systems (Witte, 2006). In the following year, 25 countries joined the initiative. They all signed the Bologna Declaration, and these circumstances made the Bologna Process possible. This all happened essentially independently of the European Union (EU), although the EU has followed the developments with great interest from the outset and, over time, has become an increasingly influential player (Corbett, 2011; Halász, 2012) in the process. These events, which unfolded from the spontaneous dialogue of national-level decision makers, led to the evolution of an operation and communication culture, which is different from what normally applies in the EU. Lažetić (2010) described Bologna as an intergovernmental, open, and non-EU policy platform. Compared to EU routines, the participating countries within the Bologna Process communicate and participate in development processes more freely and less bureaucratically. This solution is characterized by informal and less hierarchical networking, direct involvement of stakeholders, and volunteering. These operational characteristics, on the one hand, make it possible to take account of national and institution-level autonomy, and on the other hand, offer an effective, workshop-like learning environment.

Further important elements of this policy environment are continuous expansion and enrichment. On the one hand, this means the enrichment of action lines, which were not all formulated at once, but gradually unfolded during the progress of the Bologna Process. On the other hand, it refers to the continuous expansion of the scope of participating countries: EHEA currently has 48 member states. This "moving target" nature of the Bologna Process posed a continuous challenge during its implementation.

In 2005 an overarching qualifications framework based on learning outcomes (LOs) was adopted for EHEA, and all participating countries had to develop their own national qualifications framework by 2010. LOs are multipurpose tools, and their use is an important step of the Bologna Process. According to Adam (2008), they provide explicit and transparent level descriptors for national qualifications frameworks and for the previously mentioned EHEA qualifications framework, and-as will be discussed later in this article-they have an important role in the European Credit Transfer and Accumulation System (ECTS), as well. LOs can also function as effective recognition tools, thus promoting mobility. Due to the improved transparency and comparability, LOs also support quality assurance efforts. Furthermore, and perhaps the most important and widely discussed (Adam, 2008; Biggs \& Tang, 2011; Halász, 2017; Kennedy, 2007) characteristic of LOs, they are powerful curriculum design tools. As Adam (2008) explained,

Learning outcomes are key tools in the shift towards student-centred learning as they focus attention on explicit and detailed statements of what students learn-the skills, understanding and abilities we seek to develop and then test. The adoption of a learning outcomes approach focuses activity on the learner and away from the teacher. It promotes 
the idea of the teacher as a facilitator or manager of the learning process and recognises that much learning takes place outside the classroom without a teacher present. It suggests that students should be actively involved in the planning and management of their own learning, progressively taking more responsibility as he/she develops as an independent learner. (p. 13)

All these features are strongly connected to the abovementioned Bologna action lines; thus, the LO approach became a key element of the Bologna Process. The difficulty is that the LO approach is a new, complex, and previously nonexistent mode of operation in the European higher education. Thus, the significance of implementation issues increases, and that leads us to the main subject of this study: the Tuning Project.

\section{Some Important Characteristics of the Tuning Project}

The Tuning Educational Structures in Europe project started in 2000. It is funded with support from the European Commission, and its main objective is to develop a tangible approach to implementing the Bologna action lines. It follows from the complexity of this objective that the Tuning Project itself can be interpreted in several ways. According to González and Wagenaar (2008), we can describe it as a methodology and a related system of tools, which make it possible to (re)design, develop, implement, and evaluate study programs in accordance with the Bologna action lines. At the same time, Tuning can be described as platform for developing reference points - expressed in terms of LOs-at the subject area level. Besides, the Tuning Project can be seen as a network of learning communities (Cesar, 2015), wherein international/intercultural groups of higher education actors cooperate within an organized framework.

The focus of the Tuning Project is on implementing the LO approach in the EHEA. From the perspective of European higher education institutions, the implementation of this approach can be interpreted as an intrusion into an unknown world; thus, a mechanical implementation is not possible. This means that, in the case of the Tuning Project, implementation necessarily generates innovations. In connection with the creation of Tuning tools, methodology, and culture, a series of multilevel innovations can be identified. These innovations affect the key areas of higher education learning and teaching and have a great impact on organizational aspects and human resource management of higher education institutions. These Tuning innovations make the Tuning Project interesting and important to understand.

From a management point of view, the Tuning Project-although its primary goal is to implement a European-level policy-essentially works with a bottom-up approach (Birtwistle, Brown, \& Wagenaar, 2016). The related literature frequently describes it as a university-driven project. The aims of the Bologna Process require the alteration of specific institution-level processes; thus, this institution-level focus is not surprising.

The world of higher education institutions can be described with a high degree of diversification and differentiation (Ziegele \& van Vught, 2013). While in terms of basic tasks (e.g., education, research, or the "third mission" which is about transferring knowledge to the community in settings where that transfer could produce wider social or economic benefits), higher education institutions appear similar; in fact, they are multilevel and multiactor organizations (Evans \& Henrichsen, 2008; Meister-Scheytt \& Scheytt, 2005), operating in various microenvironments, and they thus define different emphases and directions in their own functional processes. This complex nature of higher education institutions has a great effect on local formation and diffusion of higher educational innovations. This also justifies the institution-level focus of Tuning Project. 
This means that the communication and operational culture of the Bologna Process, which is driven by respect for institutional autonomy, is also essential for the Tuning innovations. However, there is a difference here that is worth taking into consideration. While discussion of policy objectives and action lines took place, the Bologna Process was characterized by an essentially hierarchy-free operation, which is the basic operational culture of the EHEA. Nevertheless, the leaders of the Tuning Project have chosen a rather hierarchical, multilevel framework for the innovation processes of the Bologna implementation toolset. In the core of the structure, we can find the project coordinators who are in contact with different management committees. Most of these committees are related to subject area groups. While volunteering is fundamental here as well, and the nature of the innovation is still bottom-up, the operational culture is much more strongly layered and structured than what could otherwise be seen in the context of Bologna.

The institutional focus of the Tuning Project is also an interesting specificity from an implementation perspective. While the Tuning Project addresses national-level policy makers, it focuses primarily on higher education institutions and actors. On the one hand, it can be interpreted as the managers of the Tuning Project-knowing the importance of university autonomy and that such a degree of change cannot be carried through relying only on nationallevel decision makers-addressing the institutional level consciously. On the other hand, this strategy can be interpreted as some kind of bridging solution. The Tuning Project reaches over the national level and directly starts to facilitate bottom-up innovation processes at the institutional level, thus changing the dynamics of the national system. Multiple functions of this solution can be identified. It can support the work of those national-level decision makers and policy implementers who are committed to the Bologna Process. However, this approach is also suitable to bypass difficulties that may arise at the national level.

\section{A Deeper Analysis of the Tuning Project From a Multilevel Implementation Perspective}

\section{About Implementation in a Nutshell}

Before the detailed analysis of the Tuning Project, it is necessary to give a brief overview of the concept of implementation and the main directions of implementation research, because it greatly determines the structure and content of the following analysis.

The concept of implementation is fundamentally changed during the development of implementation theory and implementation research. The initial implementation literature-such as the classical work of Pressman and Wildavsky (1973/1984)_focuses on the explanation of policy failures, the differences between policy goals and outcomes.

The so-called top-down perspective, which followed the first rather pessimistic period of implementation research, essentially seeks to find out how and why the implementer's actions, the target group's activities, and the effects of the implementation process were consistent with the decisions made in the policy centre. The determining factors of this consistency became the dominant research areas of the top-down implementation researchers (Cerych \& Sabatier, 1992; Sabatier, 2005). A classic summary of implementation's success factors is presented in the model of Sabatier and Mazmanian (1979). This model identifies six such factors: (a) clear and consistent objectives, (b) adequate causal theory behind these objectives, (c) legally structured implementation process (veto points, incentives, sanctions), (d) committed and skilful implementing officials, (e) support of interest groups and sovereigns over time, and (f) changes in socioeconomic conditions that do not substantially undermine political support or causal theory. 
The top-down point of view later became a subject of sharp criticism (Sabatier, 2005). The criticisms were based on the fact that the top-down approach puts too much emphasis on the policy decisions and legal structure but does not take account of the interests, goals, and interpretations of a large number of actors involved in the implementation. This shortcoming was also the reason why subsequent research has, for example, questioned the positive impact of clean and consistent policy goals on implementation (Sabatier, 2005). When a large number of actors are involved in process with their own interests and motivations, overcleared or too detailed goals can be counterproductive. The clearer and more detailed the policy goals are, the more conflicts with the interests and motivations of different actors arise. Less clear objectives leave more opportunity to make deals and respond to the actions and needs of stakeholders. However, to recognize this, the complex dynamics of the motivations and activities of different relevant actors must be taken into account.

This criticism leads us to another major approach of implementation research, the bottomup perspective in the late 1970s and early 1980s. This perspective starts out from mapping the networks of stakeholders; attempts to describe the goals, strategies, and complex interactions of the actors involved; and interprets the implementation process based on that (Elmore, 1980). However, the bottom-up approach has a serious weakness: It does not deal with the special role of the policy centre and overestimates the compelling effect that peripheral actors have on the centre. Bottom-uppers thus do not pay serious attention to those considerations that the topdowners emphasized most strongly.

According to Hill and Hupe (2002), a lively debate developed between the representatives of the top-down and bottom-up approaches. This debate is a decisive element of implementation theory. Hill and Hupe also drew attention to a further interesting dimension of this debate:

...the evolution of the debate needs to be seen not simply in terms of a developing academic argument but also in its relationship to a changing perspective on the role of government in the policy process. The latter has involved what we, alongside many other contemporary writers, see as an evolution from government to governance. Central to this development was, first, the exploration of public policy delivery through private organizations using market mechanisms and public-private partnerships, followed by a recognition of the importance of networks for policy delivery. (p. 197)

Against this background, it is not surprising that, from the second half of the 1980s, more and more models have been drawn up to reconcile the top-down and bottom-up approaches (Hill \& Hupe 2002; Sabatier, 2005). These hybrid models use and consider the necessary conditions for the effective implementation defined by top-downers but, at the same time, take into account that local implementers interpret the policy goals and tools in their own environment and try to manage the implementation according to their own interests. This approach has enriched our understanding of implementation processes with important dimensions. Perhaps the most important contribution of hybrid models is that they make a distinction between the macro- and microlevels of implementation, and are thus able to handle complex, multilevel implementation processes. The current study is largely based on this synthesising approach.

\section{The Formation of Tuning Innovations and the Dynamics of Their Diffusion}

Describing the dynamics of the Tuning Project is not an easy task, due to the complexity and volume of the process. Separate discussion of the micro- and macrolevels of the project can make interpretation easier and more relevant. At the macrolevel of the project, we can identify those Tuning activities that are focused on the development of the common frame of reference, 
methodology, and toolset for all participating higher education institutions. The microlevel, in contrast, contains the system of those activities through which the processes and products of the macrolevel can take effect on the study program design and management practices of the participating institutions.

The macrolevel processes of the Tuning Project. At the macrolevel of the European Tuning Project, five key areas have been designated to orient the innovation processes. The first of these was the issue of generic/general academic competences, which was highly emphasized within the Tuning Project, while LOs are usually expressed in terms of competences. According to González and Wagenaar (2008), questionnaire-based data collection was carried out with the involvement of 998 academics, 5,183 graduates, and 944 employers from different Bologna participating countries. Graduates and employers were asked about 30 different generic competences related to three types of instrumental, interpersonal, and systemic competences. The academics were asked to rank 17 items selected from the broader generic competence list given to graduates and employers. The resulting data was further analyzed to compensate for distorting effects. Based on this extensive consultation and data collection, the Tuning Project was able to take a well-grounded position on which generic competences should be a major consideration in the design of study programs.

The second key area was related to the definition of subject-specific competences. Initially the Tuning Project focused on nine subject areas (business, chemistry, earth sciences, education, European studies, history, mathematics, nursing, and physics), and the key players of the process were the subject area groups. Although each group followed the same working method, the approaches they used-according to the different structures of the individual disciplines-were significantly different. Tuning Project coordinators described this working process as the creation of reciprocal knowledge (González \& Wagenaar, 2008). Representatives of the participating countries got to know each other's learning and teaching practices, and based on that mutual learning process, they reached a consensus on the main content of the particular discipline. The results of the work carried out by the subject area groups have been made available in separate brochures on the project website.

The third key area was the issue of the ECTS. One of the main innovations of the Tuning Project is the establishment of a connection between LOs and student workload-based ECTS credits. This redefined the role of ECTS, because the system no longer uses credits with relative value. Instead, it works with dual-determined (i.e., based on student workload and LO) credits, which thus have absolute value (González \& Wagenaar, 2008; Office for Official Publications of the European Communities, 2009; Publications Office of the European Union, 2015). This development still defines the philosophy of ECTS.

The wider discussion about learning, teaching, and evaluation processes and the quality development dimensions of these processes were the remaining fourth and fifth key areas of the European Tuning Project. In the former case modular courses, learning activities and evaluation tools were the most important factors in the design of LO-based study programs. In the latter case, crucial elements of a quality improvement system based on an internal institutional quality culture have been developed, in which curriculum evaluation takes place according to three main criteria: the learning-teaching processes, the outcomes of these processes, and the availability of resources necessary for the operation of study programs. In connection with the development of the abovementioned five key areas, a specific study program design approach emerged described in related project documents as the Tuning model. 
In the first phase of the project the first three key areas came into focus, and the related developments took place up until 2003. The developments of the fourth and fifth key areas took place in 2003-2004, and since 2004, the implementation of a developed methodology and toolset has become a key issue. Parallel to that, an opening toward doctoral programs has also become a priority (González \& Wagenaar, 2008).

In connection with the diffusion of Tuning innovations, it can be considered a major development that in 2004, the Tuning project crossed the borders of the EHEA. Thus, in many other regions of the world where there is serious need for reform in higher education-such as Latin America, Asia, Africa, and the United States-the application of Tuning methodology became possible. In terms of Tuning, it was a significant upscaling process.

Latin American Tuning (Tuning LA) was the first case in which this border crossing happened. In this process, the first phase (2004-2007) is actually regarded as a sensitizing phase (Beneitone \& Yarosh, 2015). With wide involvement of academics and higher education management actors, an intensive interinstitutional cooperation and exchange of information took place regarding the quality, effectiveness, transparency, and comparability of study programs. The main goal of this first phase was to ensure the competence-based nature of the reform. According to Beneitone and Yarosh (2015), the second phase (2011-2013) focused on the design of metaprofiles and degree profiles, the possible scenarios for new professions, the design of a system of credits (Latin American Reference Credit [CLAR]), and the joint construction of methodological strategies.

These choices of topics for Tuning LA carry interesting messages for this article. On the one hand, these are not exactly the same topics that were determined at the macrolevel of Tuning Europe. This suggests that although there was close cooperation between the European and Latin American Tuning actors, what happened here is not merely a passive transfer, but rather a rethinking/restructuring process according to regional needs. The development work on the CLAR system is a good example of this. The CLAR system (Tuning Latin America Project, 2013) is very similar to the ECTS; in fact, the key elements of the two systems are the same: 25-30 hours of student workload considered as 1 credit, with LOs also having a focal role. However, Tuning LA did not simply take ECTS, as a final product of the European development processes, and implement that finished system as it was. They organized the same negotiation and learning processes that occurred earlier in Europe. They "reinnovated" the ECTS system with European support. Thus, although the credit system development processes have produced similar results, the interpretations and learning processes of Tuning Europe and Tuning LA differed considerably. While in Europe, the credit transfer system primarily appeared as a supporting device for mobility, in Latin America, the key element was the recognition that high-quality study programs cannot be developed without a deeper understanding of learning units and their temporal needs (González and Yarosh, 2013). Thus, the issue of credits in Tuning LA linked directly to study program development. This approach apparently had an impact on European ECTS discussions. The 2015 ECTS Users' Guide (Publications Office of the European Union, 2015) has a distinct focus on designing, operating, and evaluating LO-based study programs, while this strong program-level focus is not present in the 2009 guidelines (Office for Official Publications of the European Communities, 2009).

The issue of metaprofiles also emerged in connection with the previously mentioned rethinking/restructuring process. The Tuning Project, from the beginning, put great emphasis on the definition of generic and subject-specific competences. These descriptions were initially just prioritized lists of competences. However, in connection with Tuning LA-and other regional Tuning Projects, as well-a new approach was developed (González and Yarosh, 2013) that 
focused on clustering competences. This approach led to the so-called metacompetences, and the analysis of relations between these metacompetences made it possible to develop subject area meta-profiles. The phenomenon that competences defined by workgroups of different regions were diverse in terms of number and content therefore became manageable. However, this phenomenon also indicates that the previously mentioned reinnovating process is not specific to Tuning LA but is an essential feature of regional Tuning processes. So, in fact, we can talk about such multiplications of the original Tuning Europe processes, which bind to the original project along certain key elements but can also differ from it in important aspects. Obviously, feedback can also take place in this worldwide higher education learning environment. The appearance of these parallel threads of regional programs not only enriches the Tuning Project, but also slightly reinterprets the project as a whole. Originally, Tuning was the innovation platform of the Bologna-implementation toolset. However, with the emergence of non-European Tuning Projects, a shift began to develop in the function of the project. Tuning can increasingly be described as a tool for regionalisation of higher education (Knight, 2013).

The microlevel processes of the Tuning Project. As previously mentioned, higher education institutions are multilevel and multiactor organizations operating in various microenvironments, and as such, they define different emphases and directions in their own functional processes. On the basis of this diversity, we can assume that the implementation of the Tuning approach and toolset takes place with different characteristics in different higher education organizations. It means that the microlevel is an even more complex environment for the previously described reinnovation processes. Depending on the specificities, traditions, and learning and teaching practices of the given institution, and even on the organizational role of those actors who brought the Tuning Project into the specific institution, the implementation of the Tuning toolset can generate drastically different outcomes in terms of nature, depth, and organizational validity. Similarly, there can be differences among higher education organizations as to whether they actively use the entire Tuning toolset or just certain elements of it. Therefore, the previously presented macrolevel reinnovation processes of the regional Tuning Projects also occur in connection with the transition between the macro- and the microlevel.

If we describe the microlevel as the institution- and faculty-level recreation of macrolevel innovations, than it means that microlevel implementation of Tuning is also generates innovations, and it also indicates that the microlevel of Tuning works with enormous complexity. Certain dimensions of this complexity are well founded in those research results that analyze these microlevel processes of Tuning. Two of these studies are definitely worth mentioning here.

Beneitone and Yarosh (2015) carried out a study about the institution-level impact of Tuning LA. In the first part of their research, they collected data by questionnaire from 133 Tuningparticipating institutions in 18 Latin American countries. The results showed well the diversity of institutions in adapting a certain element of the Tuning toolset, as well as organizational depth and validity of the implementation. For example, about $76 \%$ of respondent institutions stated that they applied the competence-based student-centered approach to revising or creating curricula, study programs, or plans, but only about $30 \%$ of these $76 \%$ stated that they successfully implemented this approach in the whole university. However, this $76 \%$ of positive answers is a rather encouraging result compared to the responses about the implementation of the credit system. About $55 \%$ of the institutions reported that they do not have any system of credits based on student workload. Considering that in Tuning LA, one of the key elements was the recognition that high-quality study programs cannot be developed without the application of a student workload- and LO-based credit system, it is not a very promising result. In the second part of the research, 27 institutions were selected for further investigation based on the collected data. Of these, 21 completed the whole data collection process of the second stage. Three different 
questionnaires were developed for the second research cycle: one for academic executives, one for teachers, and one for students. The results showed well the differences between the perceptions and understanding of the different actors. These results support the previously formulated expectations about the complexity of the microlevel reinnovation and learning processes.

The research conducted by Birtwistle et al. (2016) studied both the European Tuning Project and the Tuning USA project and aimed to find out whether the intended modernisation of higher education learning and teaching was actually taking place in these projects. The study covered the period from 2011 to the beginning of 2016, based on the use of quantitative and qualitative research methodology. Questionnaires were used to ask academic staff and institutional management, students, graduates, and employers. Several hundreds of stakeholders filled out the questionnaires. In addition, in-depth interviews were conducted in selected institutions, with the involvement of academic and management staff, student counsellors, and students. The research has produced interesting results. Although the research team found examples of very good practice, the authors called the overall picture worrying. As they explain,

When the findings in this Study are compared to the Bologna Implementation report 2015, the already quoted European University Association (EUA) TRENDS VII: Learning and Teaching in European Universities report and the European Students' Union (ESU) Bologna with Student Eyes 2015: Time to meet the expectation from 1999 report, it seems that the state of implementation at Higher Education institutional level is even weaker than is stated in those reports. (p. 436)

They also explain the issue of brand recognition. Tuning brand recognition is strong among those academics who were officially involved; however, it seems that beyond these participants brand recognition is weak. This indicates ineffective information flow within the higher education organizations. According to the study, the lack of consistent terminology is another crucial element. According to Birtwistle et al. (2016), "terminology is to a large extent culturally and historically bound" (p. 439). This supports the view that the microlevel implementation is strongly connected to the processes of learning and understanding. The working language of Tuning is English, but as the article noted, "using an English term does not automatically imply that such a term has the same meaning and connotation in other countries" (p. 439). Of course, understanding something and making it work are two different things. As the authors stated,

It seems that the discourse related to the paradigm shift is now landing, but that overall the actual implementation is very slow to commence or, indeed, not taking place at all. Only at places where tailored action has taken place, initiated by individuals because they were involved in specific initiatives such as Tuning. (p. 436)

It is an important experience of this research that "varied institutions display varied behaviour" (p. 449).

All these results confirm the previously described understanding of microlevel tuning implementation as a complex reinnovation process. They also show how difficult and slow it can be when we want complex multilevel and multiactor organizations to implement-or, in other words, reinvent for the organization-such an approach, which requires a paradigm shift from the vast majority of stakeholders. 


\section{Conclusion}

In the previously presented analysis, we made a distinction between the macro- and microlevel of the Tuning Project and this approach proved to be useful, because Tuning shows different dynamics at macro- and microlevel. At the macrolevel, it achieved great success in generating relevant innovations to support the renewal of the teaching and learning practices of higher education. The success of macrolevel Tuning is demonstrated by the development of the various regional Tuning Projects and their significant macrolevel results.

At the microlevel, however, the enormous complexity-resulting from the high degree of diversification and differentiation of higher education institutions, and from the large number of involved actors-slows down the implementation process and diversifies its results. This is reflected especially through those researches, which examine the implementation processes of some specific institutions.

Through the example of the Tuning Project, we saw that the implementation of a largescale higher education policy that aims to achieve a substantive change in the functioning of higher education institutions cannot be a mechanical and linear process. Tuning does not simply spread something but creates new forms of these original innovations through this recreation/reinnovation process, which is full of interesting elements of learning, problem-solving, and adaptation. Innovations of the macrolevel are reinterpreted and reinnovated at the microlevel in each higher education institution. These experiences reinforce the importance of implementation environment's dynamics and specificities, which is in line with the new directions of implementation theory.

The Tuning Project operates a very flexible innovation network, seeking and maintaining sensitive balances, which can also be interpreted as an innovation in innovation management. This is clever multilevel governance, which is increasingly emphasized in the implementation literature. Related to the Tuning Project, we could see such intelligent governance in action, which is an interesting and informative experience. The previously presented analysis may have illustrated well that Tuning-as perhaps the most important higher education innovation platform and implementation toolset nowadays-definitely deserves further attention.

\section{References}

Adam, S. (2008). Learning outcomes current developments in Europe: Update on the issues and applications of learning outcomes associated with the Bologna Process. Retrieved from https://www.academia.edu/32806775/Learning Outcomes Current Developments in Europe U pdate on the Issues and Applications of Learning Outcomes Associated with the Bologna Process GS Search

Beneitone, P., \& Yarosh, M. (2015). Tuning impact in Latin America: Is there implementation beyond design? Tuning Journal for Higher Education, 3, 187-216. GShttps://doi.org/10.18543/tjhe-3(1)2015pp187-216 GS Search

Biggs, J., \& Tang, C. (2011). Teaching for quality learning at university (4th ed.). Glasgow, Scotland: Bell and Bain. GS Search

Birtwistle, T., Brown, C., \& Wagenaar, R. (2016). A long way to go ... A study on the implementation of the learning-outcomes based approach in the EU. Tuning Journal for Higher Education, 3, 429-462. https://doi.org/10.18543/tihe-3(2)-2016pp429-463 GS Search 
Cerych, L., \& Sabatier P. (1992). Implementation of higher education reforms. In B. Clark \& G. Neave (Eds.), The encyclopedia of higher education (pp. 1003-1014). Oxford, United Kingdom: Pergamon Press. GS Search

Cesar, L. J. T. (2015). Diversity and convergence in higher education: An analysis of Tuning European Union and Tuning Latin America international cooperation programmes (Master's thesis). Department for Continuing Education Research and Educational Management, Danube University. Retrieved from https://tampub.uta.fi/bitstream/handle/10024/98968/GRADU1463134223.pdf? sequence $=1$ GS Search

Corbett, A. (2011). Ping pong: Competing leadership for reform in EU higher education 1998-2006. European Journal of Education, 46, 36-53. https://doi.org/10.1111/j.1465-3435.2010.01466.x GS Search

Elmore, F. (1980). Backward mapping: Implementation research and policy decisions. Political Science Quarterly, 94, 601-616. https://doi.org/10.2307/2149628 GS Search

Evans, N., \& Henrichsen, L. (2008). Long-term strategic incrementalism: An approach and model for bringing change in higher education. Innovative Higher Education, 33, 111-124. https://doi.org/10.1007/s10755-008-9067-y GS Search

González, J., \& Wagenaar, R. (Eds.). (2008). Universities' contribution to the Bologna Process: An introduction (2nd ed.). Bilbao, Spain: University of Duesto. Retrieved from http://www.unideusto.org/tuningeu/images/stories/Publications/ENGLISH BROCHURE FOR W EBSITE.pdf GS Search

González, J., \& Yarosh, M. (2013). Building degree profiles: The Tuning approach. Tuning Journal for Higher Education, 1, 37-69. https://doi.org/10.18543/tjhe-1(1)-2013pp37-69 GS Search

Halász, G. (2012). Az oktatás az Európai Unióban, Tanulás és együttmüködés [Education in the European Union: Learning and cooperation]. Budapest, Hungary: Új Mandátum Könyvkiadó. GS Search

Halász, G. (2017). The spread of the learning outcomes approaches across countries, subsystems and levels: A special focus on teacher education. European Journal of Education, 52, 80-91. https://doi.org/10.1111/ejed.12201 GS Search

Hill, M., \& Hupe, P. (2002). Implementing public policy. London, United Kingdom: SAGE. GS Search

Kennedy, D. (2007). Writing and using learning outcomes: A practical guide. Cork, Ireland: University College Cork. GS Search

Knight, J. (2013). A model for the regionalisation of higher education: The role and contribution of tuning. Tuning Journal for Higher Education 1, 105-125. https://doi.org/10.18543/tihe-1(1)-2013pp105-125 GS Search

Lažetić, P. (2010). Managing the Bologna Process at the European level: Institution and actor dynamics. European Journal of Education, 45, 549-562. https://doi.org/10.1111/i.1465-3435.2010.01451.x GS Search

Luzzatto, G. (2011, October 5). The European Higher Education Area (EHEA) beyond 2010: Main achievements, priorities, gaps and challenges. Hearing of the European Parliament - Committee on Culture and Education on the European Higher Education Area: State of play. Retrieved from http://www.europarl.europa.eu/document/activities/cont/201110/20111013ATT29146/20111013A TT29146EN.pdf GS Search 
Meister-Scheytt, C., \& Scheytt, T. (2005). The complexity of change in universities. Higher Education Quarterly, 59, 76-99. https://doi.org/10.1111/i.1468-2273.2005.00282.x GS Search

Office for Official Publications of the European Communities. (2009). ECTS users' guide. Retrieved from http://ec.europa.eu/dgs/education culture/repository/education/tools/docs/ects-quide en.pdf GS Search

Pressman, J. L., \& Wildavsky, A. (1984). Implementation: How great expectations in Washington are dashed in Oakland; or, Why it's amazing that federal programs work at all (3rd ed.). Berkley, CA: University of California Press. (Original work published 1973) GS Search

Publications Office of the European Union. (2015). ECTS users' guide. Retrieved from http://europass.cedefop.europa.eu/sites/default/files/ects-users-guide en.pdf GS Search

Sabatier, P. (2005). From policy implementation to policy change: A personal odyssey. In A. Gornitzka, M. Kogan, \& A. Amaral (Eds.), Reform and change in higher education: Analysing policy implementation (pp. 17-35). Dordrecht, The Netherlands: Springer. https://doi.org/10.1007/1-40203411-3 GS Search

Sabatier, P., \& Mazmanian, D. (1979). The conditions of effective implementation. Policy Analysis, 5, 481504. GS Search

Tuning Latin America Project. (2013). CLAR, Latin America reference credit. Retrieved from http://www.tuningal.org/es/publicaciones/doc download/107-clar-latin-american-reference-creditenglish-version

Witte, J. K. (2006). Change of degrees and degrees of change: Comparing adaptations of European higher education systems in the context of the Bologna Process (doctoral dissertation). Center for Higher Education Policy Studies, University of Twente. Retrieved from https://www.utwente.nl/en/bms/cheps/education/phd-page/cheps-alumni-and-theirtheses/2006wittedissertation.pdf GS Search

Ziegele, F., \& van Vught, F. (2013). "U-Multirank” und “U-Map” als Ansätze zur Schaffung von Transparenz im europäischen und globalen Hochschulsystem, Konzepte und Erfahrungen ["U-Multirank" and "U-Map" as two approaches towards increasing transparency in the European and in the global higher education system: Concepts and experiences]. Beiträge zur Hochschulforschung, 35, 5074. GS Search 